\title{
Experimental Investigation of a Monopropellant Thruster Using Nitrous Oxide
}

\author{
Luciano Hennemann¹, José Carlos de Andrade", Fernando de Souza Costa1
}

\begin{abstract}
Nitrous oxide is a monopropellant with potential for use in propulsion systems for orbit correction, positioning and attitude control of satellites. This paper presents experimental results with a $2 \mathrm{~N}$ thruster prototype employing nitrous oxide gas decomposed by a rhodium oxide catalyst supported on alumina. Initially, the thruster design, the test bench and test procedures are described. Then the main experimental results, including thrust curves, mass flow rates, pressures and temperatures along the thruster are presented for pulsed operation. At the end specific impulses, characteristic velocities and thruster efficiencies are determined, thus indicating a catalytic decomposition efficiency of about $88 \%$.
\end{abstract}

KEYWORDS: Satellite propulsion, Nitrous oxide, Rhodium oxide catalyst, Propulsive efficiency.

\section{INTRODUCTION}

Several factors, such as atmospheric drag, the gravitational attractions of the Moon and the Sun, the non-uniformity of the Earth gravitational field and solar radiation contribute to change the attitude and move satellites from their original orbits (Sutton, 2001). For example, in geo-stationary satellites, Luni-solar perturbations cause a north-south drift that requires corrections of $50 \mathrm{~m} / \mathrm{s} /$ year and the variation of the Earth gravitational field can generate an east-west drift of 1 degree in 60 days (Stark and Swinerd, 2003). Therefore, the use of an orbit correction and attitude control system is necessary for continuity of the normal service conditions of a satellite.

At first, the control system of the rocket launcher provides input for the upper propulsion stages, for initial stabilization in orbit, alignment and firing of small thrusters (actuators). These are responsible for positioning and attitude control of the satellite in its initial orbit, having sensors, algorithms and actuators to aid in these tasks. The sensors determine the satellite's instantaneous position in orbit and provide reference to an algorithm that controls the thrusters to reposition the satellite (Plumlee and Steciak, 2004; Sanscrainte, 1961).

Liquid propellant thrusters can generate high specific impulses and thrusts, and allow precise control of thrust and exhaustion kinetic energy. In general, these systems use pressurizing tanks with an inert gas (nitrogen or helium). In bipropellant systems, the fuel and oxidant are injected, mixed and burned in the combustion chamber to form gaseous products at elevated temperatures that are ejected through a nozzle to generate thrust. Monopropellant thrusters use a single propellant decomposed by a catalyst, or by heating, in order to form hot gases to be ejected at high speeds through the nozzle. 
Both systems can operate in pulsed mode for attitude control and orbit correction and stay idle long periods of time. However, liquid monopropellant systems can provide smaller and more precise pulsed firings and have a lower number of components compared to bipropellant systems. These can be expensive and difficult to be applied in some cases, and require care in the design to operate with zero gravity (Brown, 1995; Humble et al., 1995).

The use of monopropellant or bipropellant systems depends on the desired application. Comparatively, bipropellant systems have specific impulses between $300 \mathrm{~s}$ to $450 \mathrm{~s}$, producing a thrust up to $1.2 \times 10^{7} \mathrm{~N}$. Monopropellant systems operate with specific impulses of $130 \mathrm{~s}$ to $280 \mathrm{~s}$ providing $0.5 \mathrm{~N}$ to $500 \mathrm{~N}$ of thrust (Makled and Belal, 2009). Nevertheless, monopropellant systems are more commonly used than bipropellant systems for orbit correction and attitude control of satellites due to the low thrust levels required, lower mass and greater simplicity in construction.

Hydrazine $\left(\mathrm{N}_{2} \mathrm{H}_{4}\right)$ is the most used liquid monopropellant for space applications; however, in the last decade, there has been a significant interest for using green monopropellants, such as nitrous oxide $\left(\mathrm{N}_{2} \mathrm{O}\right)$ and hydrogen peroxide $\left(\mathrm{H}_{2} \mathrm{O}_{2}\right)$. Nitrous oxide can be used as an energy source and for generation of oxygen on board spacecrafts or launch rockets, in cold gas propulsion systems for attitude control, in monopropellant or bipropellant thrusters, in gas generator systems, turbine operation and resistojets (Zakirov et al., 2000).

A research team from the University of Surrey, in England, has tested several catalysts for decomposition of nitrous oxide. The tests were performed without choking the nozzle, at ambient pressure. The reported temperature for initiation of decomposition was $250^{\circ} \mathrm{C}$ and the final decomposition temperature reached $1500^{\circ} \mathrm{C}$. It was concluded that the catalytic decomposition process depends on the mass flow rate and also that the start of the catalytic decomposition can be faster with higher preheat energy supply (Zakirov et al., 2001).

At Tsinghua University, in China, hot tests were made with nozzle chocking. Based on the research from the University of Surrey, the catalytic bed dimensions were reduced and the transient preheat time decreased from 15 min to $52 \mathrm{~s}$ (Zakirov and Li, 2004). Also in Tsinghua, a computational model of the operation of a nitrous oxide monopropellant thruster was developed (Zakirov and Zhang, 2008).

In Surrey and Tsinghua Universities, the focus of research was in the decomposition of nitrous oxide. In contrast, researchers at Stanford University evaluated the characteristic velocity efficiency and predicted the thrust of a nitrous oxide thruster, although without providing information on the thruster design. A gas generator was developed to operate at high mass flow rates of nitrous oxide ranging from $0.9 \mathrm{~g} / \mathrm{s}$ to $2.3 \mathrm{~g} / \mathrm{s}$, thus obtaining characteristic velocities with high efficiency in steady state. The mixing of $\mathrm{CH}_{4}$ and $\mathrm{N}_{2} \mathrm{O}$ was also studied for initiation of the reaction (Lohner et al., 2007; Scherson and Lohner, 2009).

In the University of Beihang, in China, the effect of the catalytic decomposition of nitrous oxide on specific impulse was studied in a $140 \mathrm{mN}$ monopropellant thruster. Based on preliminary studies with a numerical model considering effects of turbulence, the thruster was designed and tested in vacuum conditions. The catalyst used was alumina impregnated with iridium; yielding decomposition starting around $523 \mathrm{~K}$. The experiments have shown that the bed length influences the nitrous oxide catalytic decomposition with longer beds, favoring complete decomposition. Therefore, it was found that to achieve high specific impulse, the optimization of the catalyst bed is required to assure that the products reach a high temperature at the nozzle inlet. On the other hand, effects such as heat losses to the environment cooperate negatively to reaction temperature. A model for the consumption of nitrous oxide and its self-pressurizing conditions in the tank was also developed. It follows from experimental and simulated data that the tank pressure decreases during the feeding process of self-pressurized nitrous oxide. Large pressure drops in the final stages of the feeding process can interfere with the required mass flow (Cai et al., 2011).

Therefore, this work describes an experimental study of a $2 \mathrm{~N}$ monopropellant thruster using nitrous oxide as propellant. The propulsive parameters are determined experimentally and the decomposition performance is evaluated. A glow-plug heater system and a rhodium oxide catalyst supported on alumina were used to heat and decompose the gaseous propellant.

\section{NITROUS OXIDE CHARACTERISTICS}

Nitrous oxide is a low cost non-toxic, non-flammable, nonexplosive, non-harmful, and easy to purchase or manufacture propellant (Merrill, 2008; Junior, 2009). It remains stable under normal conditions and is compatible with materials with simple structure; it is storable as a compressed gas or a liquid in wide temperature ranges, theoretically limited by its triple point $\left(-90.8^{\circ} \mathrm{C}\right)$. However its storage is recommended in temperatures between $-34^{\circ} \mathrm{C}$ to $60^{\circ} \mathrm{C}$. $\mathrm{N}_{2} \mathrm{O}$ decomposes exothermically with aid of a catalyst or thermally, and can be stored in saturation 
conditions in about 50.8 bar at $20^{\circ} \mathrm{C}$. A comparison of nitrous oxide with other monopropellants is shown in Table 1.

Nitrous oxide starts decomposition between $520^{\circ} \mathrm{C}$ to $850^{\circ} \mathrm{C}$, forming mostly nitrogen $\left(\mathrm{N}_{2}\right)$ and oxygen $\left(\mathrm{O}_{2}\right)$, and releasing heat. Due to the high amount of energy needed to initiate the decomposition, catalysts are used to reduce the activation energy of the reaction, then yielding a lower decomposition temperature, around $250^{\circ} \mathrm{C}$. However, the system must be preheated to this temperature to start the exothermic decomposition and attain a self-sustaining reaction. Reaching this condition, the adiabatic decomposition temperature is around $1640^{\circ} \mathrm{C}$, producing a theoretical specific impulse of $206 \mathrm{~s}$ (Zakirov et al., 2001).

\section{NITROUS OXIDE DECOMPOSITION}

The chemical mechanism of the gas phase decomposition of nitrous oxide starts with:

$\mathrm{N}_{2} \mathrm{O}+\mathrm{M} \rightarrow \mathrm{N}_{2}+\mathrm{O}+\mathrm{M}$

where $\mathrm{M}$ is a third body (Karabeyoglu et al., 2008). The $\mathrm{O}$ radical reacts with $\mathrm{N}_{2} \mathrm{O}$ according to the two parallel reactions:

$\mathrm{N}_{2} \mathrm{O}+\mathrm{O} \rightarrow \mathrm{NO}+\mathrm{NO}$

$\mathrm{N}_{2} \mathrm{O}+\mathrm{O} \rightarrow \mathrm{N}_{2}+\mathrm{O}_{2}$

The $\mathrm{O}$ radical can be eliminated by a termolecular homogeneous recombination:
$\mathrm{O}+\mathrm{O}+\mathrm{M} \rightarrow \mathrm{O}_{2}+\mathrm{M}$

or by a heterogeneous recombination:

$\mathrm{O}+$ wall $\rightarrow \frac{1}{2} \mathrm{O}_{2}+$ wall

Secondary reactions involved mainly in the formation of NO are:

$\mathrm{NO}+\mathrm{O}+\mathrm{M} \rightarrow \mathrm{NO}_{2}+\mathrm{M}$

$\mathrm{N}_{2} \mathrm{O}+\mathrm{NO}_{2} \rightarrow \mathrm{N}_{2}+\mathrm{O}_{2}+\mathrm{NO}$

$\mathrm{NO}_{2}+\mathrm{O} \rightarrow \mathrm{NO}+\mathrm{O}_{2}$

$\mathrm{NO}+\mathrm{N}_{2} \mathrm{O} \rightarrow \mathrm{N}_{2}+\mathrm{NO}_{2}$

The previous equations can be combined, yielding the following global reactions:

$\mathrm{N}_{2} \mathrm{O} \rightarrow \mathrm{N}_{2}+\frac{1}{2} \mathrm{O}_{2} ; \Delta \mathrm{H}=-1865 \mathrm{~kJ} / \mathrm{kg}$

$\mathrm{N}_{2} \mathrm{O} \rightarrow \mathrm{NO}+\frac{1}{2} \mathrm{~N}_{2} ; \Delta \mathrm{H}=+19.17 \mathrm{~kJ} / \mathrm{kg}$.

The reaction involving $\mathrm{N}_{2} / \mathrm{O}_{2}$ is exothermic and the $\mathrm{NO} / \mathrm{N}_{2}$ reaction is endothermic.

Catalytic reactions offer advantages since they favor the $\mathrm{N}_{2} / \mathrm{O}_{2}$ self-sustaining reaction and improve the reaction efficiency (Wilson et al., 2012; Lohner et al., 2007; Zakirov and Zhang, 2008). The catalytic decomposition of nitrous oxide starts

Table 1. Comparison of nitrous oxide with others monopropellants (Zakirov et al., 2001).

\begin{tabular}{|c|c|c|c|}
\hline Propellant & Nitrous Oxide & Hydrogen Peroxide & Hydrazine \\
\hline Chemical formula & $\mathrm{N}_{2} \mathrm{O}$ & $\mathrm{H}_{2} \mathrm{O}_{2}$ & $\mathrm{~N}_{2} \mathrm{H}_{4}$ \\
\hline Theoretical $I_{\text {sp }}(\mathrm{s})$ & 206 & 179 & 245 \\
\hline Storable & yes & yes & yes \\
\hline Density $\left(\mathrm{kg} / \mathrm{m}^{3}\right)$ & 745 at $20^{\circ} \mathrm{C}$ and 52 bar & 1347 & 1004 \\
\hline Vapor pressure $($ bar $)$ & 50.8 at $20^{\circ} \mathrm{C}$ & 0.00345 at $20^{\circ} \mathrm{C}$ & 0.0214 at $26,7^{\circ} \mathrm{C}$ \\
\hline Storage temperature $\left({ }^{\circ} \mathrm{C}\right)$ & -34 to 60 & -7 to 38 & 9 to 60 \\
\hline Toxic & no & burns skin & very toxic \\
\hline Flammable & no & no & yes \\
\hline
\end{tabular}

$I_{\mathrm{sp}}$ in vacuum conditions with nozzle expansion ratio 200; all propellants stored in liquid state; hydrogen peroxide $89 \% \mathrm{~m} / \mathrm{m}$. 
with the adsortion of a $\mathrm{N}_{2} \mathrm{O}$ molecule in an active site on the catalyst surface. After that, the $\mathrm{N}_{2}$ molecule is released while the oxygen atom remains adsorved on the active site. At last, the oxygen atom is released when it combines with another oxygen atom in a nearby active site, forming $\mathrm{O}_{2}$ or by direct reaction with another $\mathrm{N}_{2} \mathrm{O}$ molecule. These steps are described by:

$$
\mathrm{N}_{2} \mathrm{O}+[]-\mathrm{M} \rightarrow \mathrm{N}_{2} \mathrm{O}-\mathrm{M}
$$

$$
\mathrm{N}_{2} \mathrm{O}-\mathrm{M} \leftrightarrow \mathrm{N}_{2}+\mathrm{O}-\mathrm{M}
$$

$2 \mathrm{O}-\mathrm{M} \leftrightarrow \mathrm{O}_{2}+[-\mathrm{M}$

$$
\mathrm{N}_{2} \mathrm{O}+\mathrm{O}-\mathrm{M} \rightarrow \mathrm{N}_{2}+\mathrm{O}_{2}+[]-\mathrm{M}
$$

In reactions (12-15) the $\mathrm{O}-\mathrm{M}$ term refers to an oxygen radical and the $\mathrm{N}_{2} \mathrm{O}-\mathrm{M}$ term refers to a $\mathrm{N}_{2} \mathrm{O}$ molecule adsorved on the catalyst surface. The []-M term corresponds to an empty site on the catalyst surface. During $\mathrm{N}_{2} \mathrm{O}$ decomposition, the adsortion of oxygen radicals coming from the catalytic surface is often considered a limiting factor. For this reason, the decomposition rate of $\mathrm{N}_{2} \mathrm{O}$ is intimately linked to the bind energy between the catalyst metal and the oxygen atom (Scherson and Lohner, 2009; Kapteijn et al., 1996).

\section{CATALYST FOR $\mathbf{N}_{2} \mathrm{O}$ DECOMPOSITION}

A catalyst is used to provide a rapid propellant decomposition, without changing the global reaction. The reactants bind chemically to the surface of the catalyst active sites, which are atoms or groups of atoms available for reaction. When the catalyst is solid, the active material is composed of metal or metal oxides which are dispersed over a high surface area material, increasing the contact area between reactants and active sites (Batta et al., 1962; Vieira et al., 2003). In the case of gaseous nitrous oxide, this is obtained by making it pass through a material with transition metals, such as $\mathrm{Ir}, \mathrm{Rh}, \mathrm{Ru}$, $\mathrm{Ni}, \mathrm{Co}, \mathrm{Cu}$ or $\mathrm{Zr}$.

There are several characteristics which affect the catalyst performance. The most important one is the decomposition limiting factor. The reaction can be controlled by different processes:
- Chemical kinetics, limited by the speed of $\mathrm{N}_{2} \mathrm{O}$ adsorption on the catalyst, that is, the speed of combination of $\mathrm{N}_{2} \mathrm{O}$ with a rhodium molecule in an active site and release of oxygen and nitrogen;

- Diffusion in the catalyst pores, where the reaction is limited by diffusion of reactants and products into and out of these microscopic pores; and

- Convection in the diffusion boundary layer around each pellet catalyst, which cannot carry the products and reactants from the surface.

Knowing which of these modes is important will determine how the catalyst bed should be sized (Figueiredo and Ribeiro, 1989).

Tests are needed also to determine the critical temperature range. It is necessary to know when the decomposition reaction changes from slow to fast and complete. The catalyst must be tested to determine the maximum temperature at which it can be used without deterioration of its properties. This should be checked since the active material ( $\mathrm{Rh}, \mathrm{Ru}, \mathrm{Ir})$ to be deposited on the support material surface also will be subjected to high temperatures. Placing these active elements at very high temperatures can cause their vaporization and removal of the support surface, destroying the catalyst (Figueiredo and Ribeiro, 1989).

Being commercially available and having a relatively low cost, supports based on alumina $\left(\mathrm{Al}_{2} \mathrm{O}_{3}\right)$ are widely used for catalytic purposes in propulsion. The aluminum oxide is formed at room temperature in $\gamma-\mathrm{Al}_{2} \mathrm{O}_{3}$ phase and has an open structure consisting of amorphous aggregates of $\mathrm{Al}_{12} \mathrm{O}_{18}$. When the temperature increases (around $1200^{\circ} \mathrm{C}$ ) aluminum oxide goes through different phases irreversibly to form $\alpha-\mathrm{Al}_{2} \mathrm{O}_{3}$ which is the final stage of its internal structure. Although the stages of transition are not well understood, it is well known that for each transition, the available surface area per gram of oxide decreases significantly, causing a decrease in the number of active sites available for decomposition (Arai and Machida, 1996; Vafai, 2005).

Because of its ready availability and decomposition efficiency, a catalyst of rhodium $\left(\mathrm{Rh}_{2} \mathrm{O}_{3}\right)$ oxide supported on alumina $\left(\mathrm{Al}_{2} \mathrm{O}_{3}\right)$ was chosen to decompose nitrous oxide in a $2 \mathrm{~N}$ thruster prototype. Catalyst pellets (cylindrical extrudate) approximately $2 \mathrm{~mm}$ diameter and $3 \mathrm{~mm}$ length were used, containing $5 \%$ by volume of rhodium oxide. The pellets are shown in Fig. 1. 


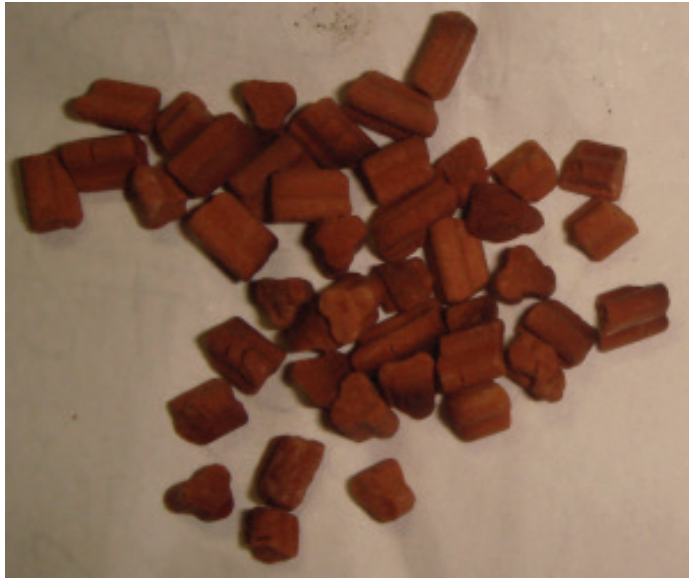

Figure 1. $\mathrm{Rh}_{2} \mathrm{O}_{3} / \mathrm{Al}_{2} \mathrm{O}_{3}$ catalyst.

\section{THRUSTER DESIGN}

The thruster design was based on a performance theoretical study carried out with aid of CEA2 NASA (2012) program. This program initially determines the chemical equilibrium composition and temperature in the chamber for constant pressure and enthalpy, through minimization of the Gibbs free energy. Then it solves the conservation equations for one-dimensional isentropic steady flow along the nozzle considering equilibrium or frozen conditions. As input parameters, the properties of pure nitrous oxide gas were considered at a temperature of $298.16 \mathrm{~K}$, atmospheric pressure of 0.95 bar, 5 bar pressure in the chamber and assuming frozen flow in the nozzle. Data obtained with the NASA CEA 2 code are shown in Tables 2 and 3 . Table 3 confirms that the main decomposition products are $\mathrm{O}_{2}$ and $\mathrm{N}_{2}$. Table 4 shows some dimensions of the nozzle and the mass flow rate of propellant calculated to yield $2 \mathrm{~N}$ thrust.

Estimates of the length and diameter of the catalytic chamber were made based on the literature of monopropellant catalytic thrusters (Lohner et al., 2007; Scherson and Lohner, 2009; Cai et al., 2011). Thus, the reference values adopted for initial design of the catalyst chamber were $15 \mathrm{~mm}$ in diameter and $70 \mathrm{~mm}$ in length (D15L70). All thruster parts (flange injection, chamber, catalyst bed and nozzle) were manufactured in 316 stainless steel. Computational views of thruster (3D drawings) are shown in Fig. 2, whereas Fig. 3a depicts the disassembled thruster and Fig. $3 \mathrm{~b}$, thruster mounted in the thrust balance.
Table 2. Thruster theoretical parameters.

\begin{tabular}{|c|c|c|c|}
\hline $\begin{array}{c}\text { Thruster } \\
\text { parameters }\end{array}$ & $\begin{array}{c}\text { Thruster } \\
\text { chamber }\end{array}$ & $\begin{array}{c}\text { Nozzle } \\
\text { throat }\end{array}$ & $\begin{array}{c}\text { Nozzle } \\
\text { exhaustion }\end{array}$ \\
\hline$P($ bar $)$ & 5.0000 & 2.7262 & 0.9505 \\
\hline$T(K)$ & 1906.92 & 1658.40 & 1293.97 \\
\hline$\rho\left(k g / m^{3}\right)$ & 0.92529 & 0.58010 & 0.25924 \\
\hline$c_{\mathrm{p}}(k J / k g / K)$ & 1.2403 & 1.2213 & 1.1842 \\
\hline$\gamma$ & 1.2961 & 1.3021 & 1.3146 \\
\hline $\mathrm{Mach}$ & 0.000 & 1.000 & 1.758 \\
\hline$A_{\mathrm{e}} / A_{\mathrm{g}}$ & - & 1.000 & 1.4343 \\
\hline$c^{*}(m / s)$ & - & 1101.8 & 1101.8 \\
\hline$C_{\mathrm{F}}$ & - & 0.7099 & 1.1076 \\
\hline$I_{\mathrm{vac}}(m / s)$ & - & 1383.0 & 1520.9 \\
\hline$I_{\mathrm{sp}}(m / s)$ & - & 782.2 & 1220.4 \\
\hline
\end{tabular}

$P=$ chamber pressure; $T$ = chamber temperature; $\rho$ = density of products; $C_{\mathrm{p}}=$ specific heat of the products; $\gamma=$ ratio of specific heats of products; Mach = Mach number; $A_{\mathrm{e}}=$ exhaustion area; $A_{\mathrm{g}}=$ throat area; $C^{*}=$ characteristic velocity; $C_{\mathrm{F}}=$ coefficient of thrust;

$I_{\text {vac }}=$ specific impulse in vacuum; $I_{\mathrm{sp}}=$ specific impulse with adapted nozzle.

Table 3. $\mathrm{N}_{2} \mathrm{O}$ decomposition products.

\begin{tabular}{|c|c|}
\hline Products & Molar fractions \\
\hline $\mathrm{NO}$ & 0.06370 \\
\hline $\mathrm{O}$ & 0.00008 \\
\hline $\mathrm{NO}_{2}$ & 0.00004 \\
\hline $\mathrm{O}_{2}$ & 0.32988 \\
\hline $\mathrm{N}_{2}$ & 0.66327 \\
\hline
\end{tabular}

Table 4. Thruster parameters and dimensions.

\begin{tabular}{|c|c|}
\hline Parameters & Values \\
\hline$A_{\mathrm{g}}\left(m m^{2}\right)$ & 3.61 \\
\hline$D_{\mathrm{g}}(\mathrm{mm})$ & 2.14 \\
\hline$A_{\mathrm{e}}\left(\mathrm{mm}^{2}\right)$ & 5.17 \\
\hline$D_{\mathrm{e}}(\mathrm{mm})$ & 2.56 \\
\hline$\dot{m}(/ \mathrm{s})$ & 1.63 \\
\hline
\end{tabular}

\section{TEST BENCH}

A test bench was used to determine thrust, mass flow rate, temperatures and pressures in the supply line and in the thruster. A schematic of the test bench is showed in Fig. 4. It contains 

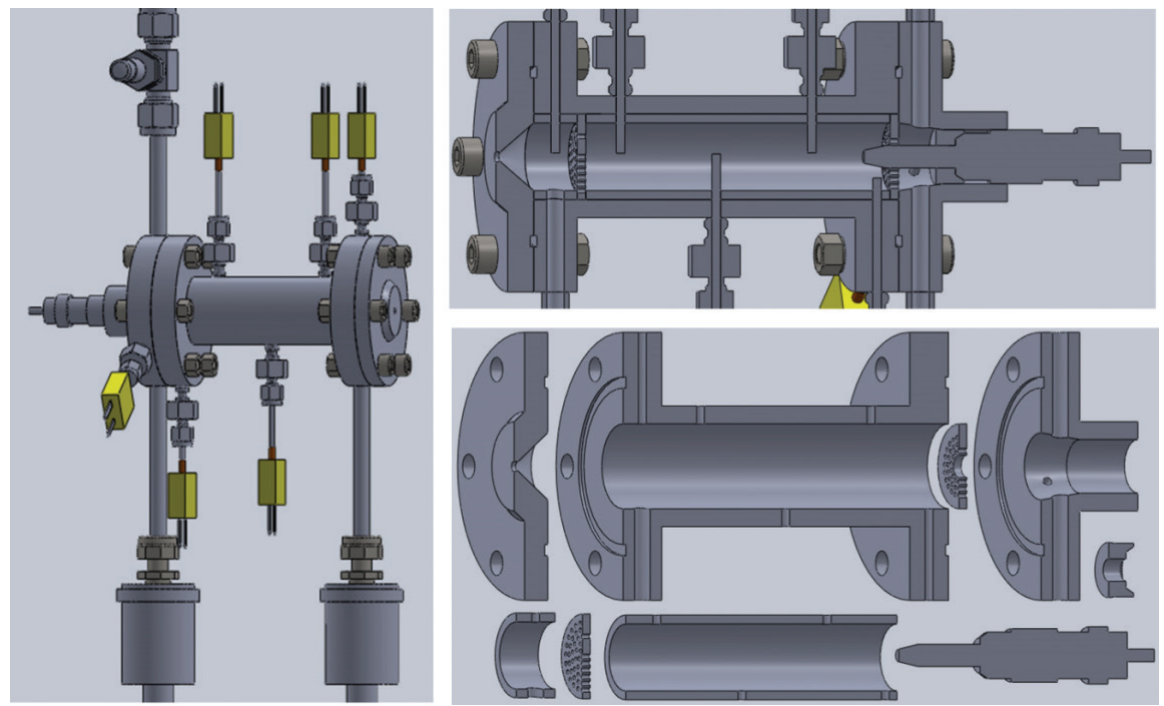

Figure 2. 3D drawings of the thruster with instrumentation and cut views.

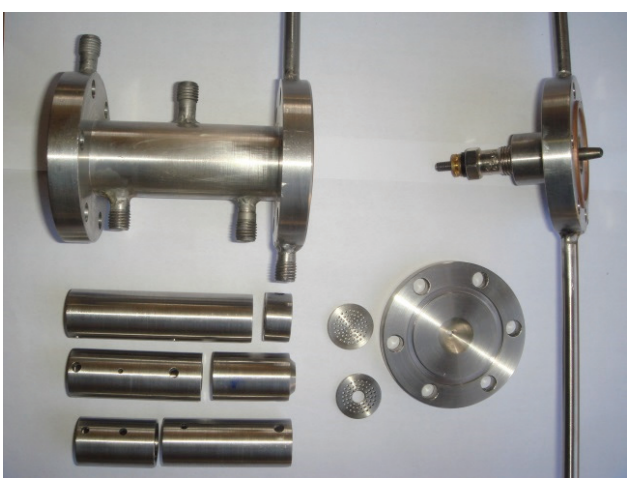

(a)

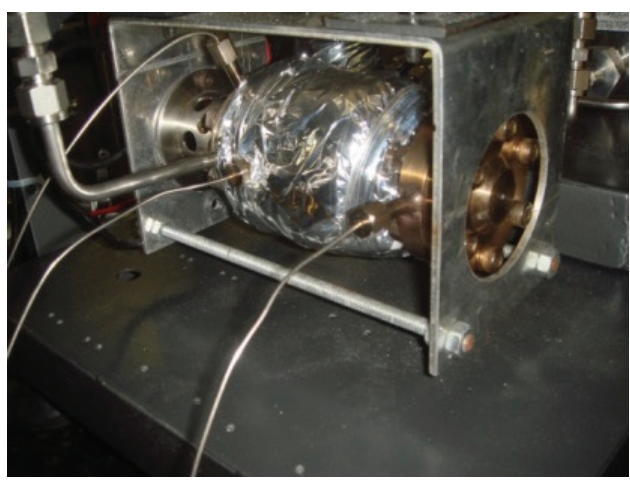

(b)

Figure 3. Thruster photos.

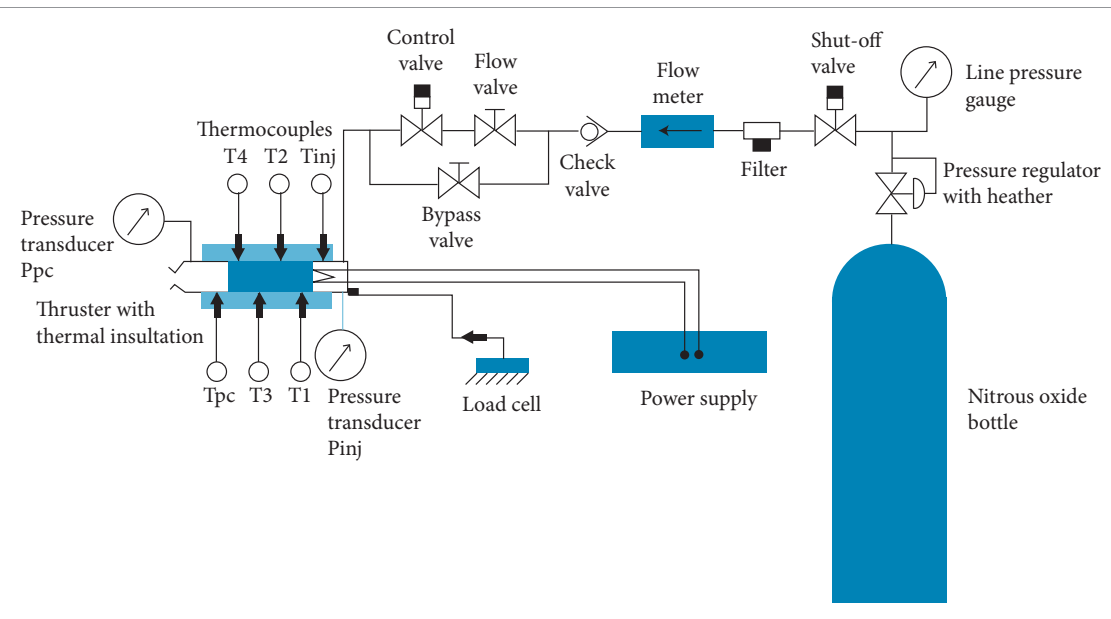

Figure 4. Test bench scheme. 
a gas cylinder with nitrous oxide (99.99\%), a heated pressure regulator, sintered filters in the gas inlet valves, manual lock valves, two-way solenoid valve with direct action, check valve, pressure transmitters, K-type thermocouples, HBM load cell with $5 \mathrm{~N}$ capacity $( \pm 0.01 \mathrm{~N})$, and a Sevenstar nitrous oxidizer mass flow meter. Preheating of the nitrous oxide to start decomposition was performed by a Duratherm Bosch glowplug placed at the entrance of the catalyst bed, as depicted in Fig. 2. The injection temperature, i.e., the gaseous nitrous oxide temperature at the entrance of the catalyst bed, was adjusted by a temperature controller (Novus 480I) which monitored the glow-plug heating.

A data control system using a National Instruments SC-2345 rack, TCC02 modules (for signals in mV), FT01 modules (with channels 0-10 V), Compact Daq USB module (extra channels of analog inputs and communication module) and a PCI-6221 data acquisition board were used for observations of the experiments variables in real time. A Labview control software monitored variables of pressure, mass flow rate, thrust, temperature and operation of the glow-plug. For this purpose, analog and digital input/output were used, providing data on a computer in graphical form and saving in its database.

\section{RESULTS AND DISCUSSION}

A pressure of 7.5 bar at the exit of the regulator valve was adopted to provide the total pressure drop on the various devices installed before the thruster. Once the temperature (thermocouple $T_{\text {inj }}$ ) measured in the glow-plug heater section reached $220^{\circ} \mathrm{C}$ the injection of nitrous oxide was performed. This is evidenced in Fig. 5 which shows that a pulse with a mass flow rate $(Q)$ of $1.6 \mathrm{~g} / \mathrm{s}$ increased rapidly the catalytic bed temperature, thus indicating the occurrence of catalytic decomposition.

Locations of $T_{\text {inj }}, T_{1}, T_{2}, T_{3}$ and $T_{4}$ thermocouples along the catalytic chamber can be seen in Figs. 2 and $4 . T_{\mathrm{pc}}$ is the measured temperature after the catalytic bed (post-chamber). Prior to testing, pre-heating was kept for several minutes for thermal stabilization of the catalyst bed.

After the preheating period, the glow plug temperature controller was turned off. The mass flow rate was gradually increased to the nominal flow rate and heating was maintained only by the decomposition of $\mathrm{N}_{2} \mathrm{O}$ flow. Under these conditions, it was possible to apply multiple sequences of pulses with different duty cycles, i.e., periods with mass flow on and off. Very long shots could compromise the thruster and thermocouples, due to

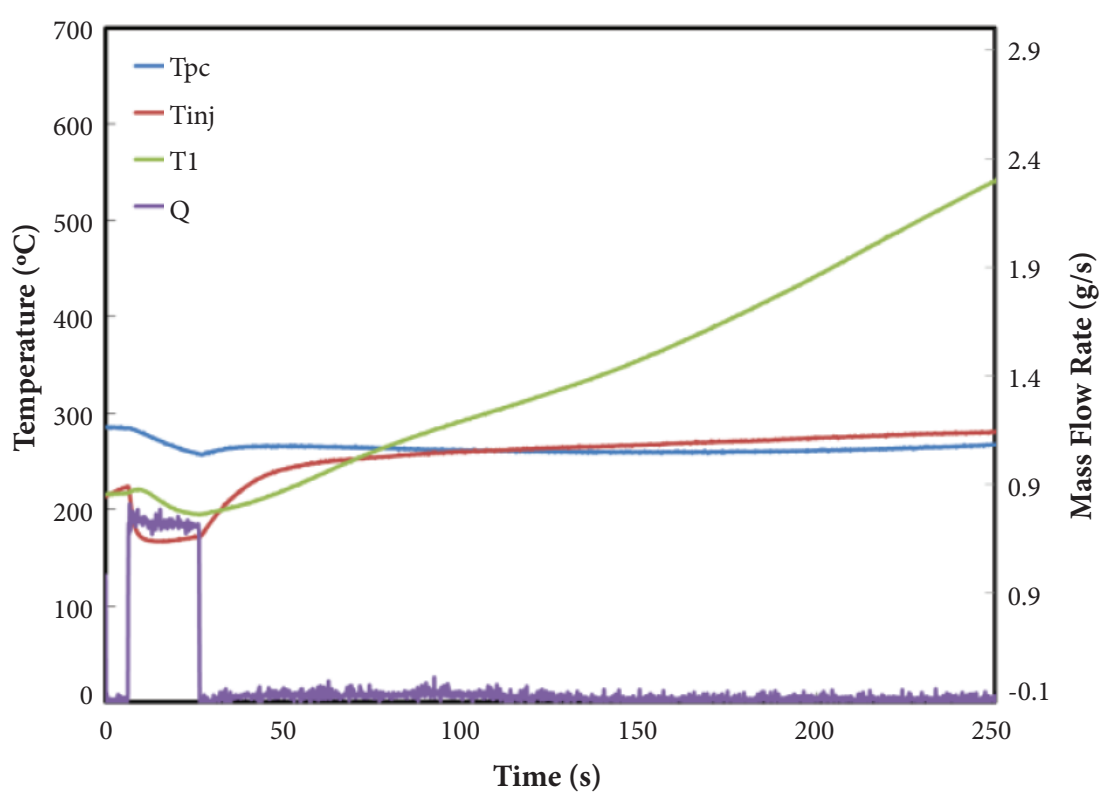

Figure 5. Initial heating using $\mathrm{N}_{2} \mathrm{O}$. 
the high temperatures that could be reached in the bed. During intervals, there occurred a temperature uniformization along the thruster, especially in the catalytic bed.

Figure 6 shows curves of pressures, temperatures and mass flow rates measured in the thrust balance. A sequence of 5 pulses with $25 \mathrm{~s}$ on and $10 \mathrm{~s}$ off is shown, followed by sequences of 3

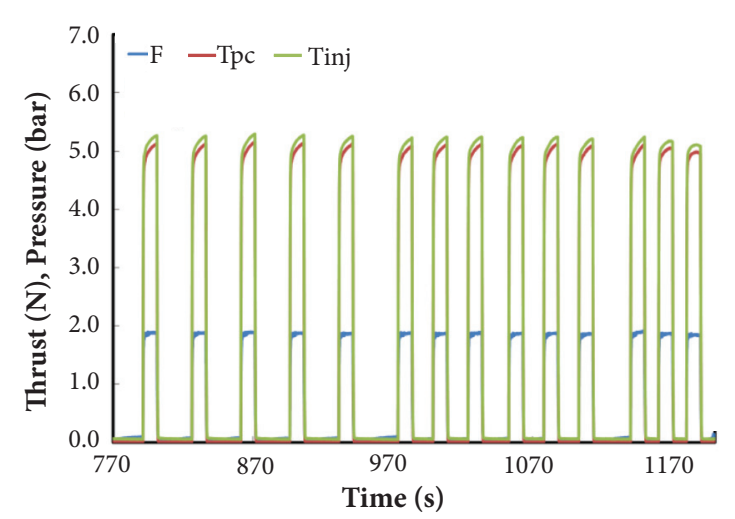

(a)

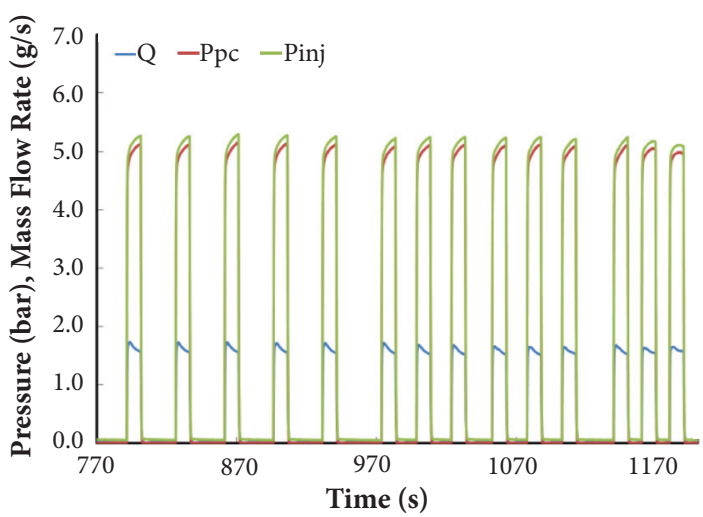

(b)

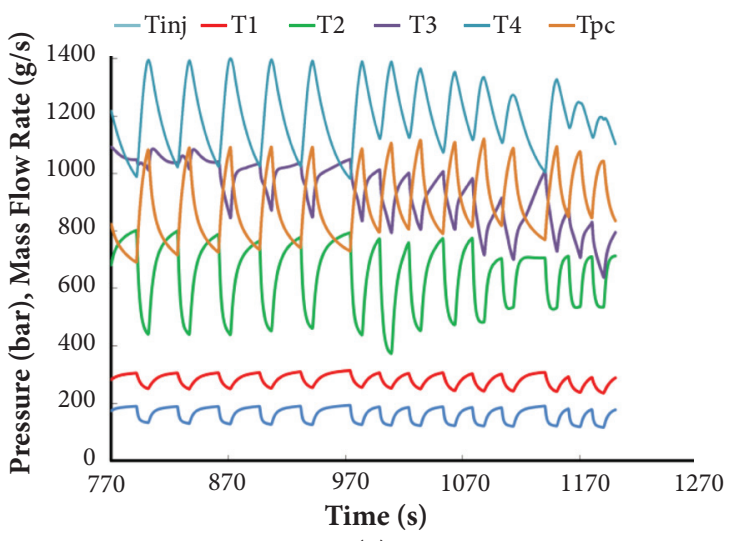

(c) pulses with $15 \mathrm{~s}$ on and $10 \mathrm{~s}$ off. It is observed that the injection pressures $\left(P_{\text {inj }}\right)$ and post-chamber $\left(P_{\mathrm{pc}}\right)$ reached 5.29 bar and 5.15 bar, respectively. The temperature at the end of the catalytic bed $\left(T_{4}\right)$ reached $1400^{\circ} \mathrm{C}$ with an average mass flow rate $(Q)$ of $1.65 \mathrm{~g} / \mathrm{s}$. The thrust $(F)$ measured on the load cell reached 1.93 $\mathrm{N}$, close to the design value of $2 \mathrm{~N}$.

Figure 7 shows the gas temperature evolution inside the catalytic chamber of the thruster. A MATLAB algorithm using a cubic interpolation method was developed to determine the temperature distributions during the thermal-catalytic decomposition process.

Taking as reference the pulse in the interval of $860 \mathrm{~s}$ to $900 \mathrm{~s}$ in Fig. $6 \mathrm{c}$, it was observed that the highest temperature $\left(1400^{\circ} \mathrm{C}\right)$ was measured by the thermocouple located at $62 \mathrm{~mm}$ from the injection, as shown in Figs. 2 and 4. This corresponds to the last catalytic bed thermocouple $\left(T_{4}\right)$. The maximum temperature reached at the end of the catalytic chamber indicates a bed with optimum length. The hot expanding gases from decomposition pass through the post-chamber and follow to the nozzle for generating thrust.

Pulses present similar profiles for several sequences and in different periods. However, the fatigue of the catalyst can be observed in the range of $1136 \mathrm{~s}$ to $1200 \mathrm{~s}$ in Fig. 6, where pulses are deliberately shown with a decrease in catalyst efficiency. This is due to the pellet contraction and loss of rhodium oxide. The contraction of the pellets is caused by the low calcination temperatures and phase change of alumina, as was previously described by Arai and Machida (1996). The rhodium oxide loss is due to the high temperatures reached in the catalytic bed. The decrease in pellet volume also creates preferential paths for $\mathrm{N}_{2} \mathrm{O}$ flow which pass through the catalytic bed without decomposition. Besides, it causes a decrease in the catalyst specific area, reducing the area of active sites available for catalytic reaction. If the surface available for decomposition is internal to the pellets, with the alumina retraction the active sites become inaccessible for $\mathrm{N}_{2} \mathrm{O}$, preventing its decomposition. However, there was no clustering of catalyst grains or weight loss.

There is also a loss of efficiency concerning the reduction of the adsorption capacity of the molecules of $\mathrm{N}_{2} \mathrm{O}$, as seen in the last three pulses in Figs. 6, 8 and 9. This may be explained by the adsortion of water and oxygen which reduces the number of active sites available for $\mathrm{N}_{2} \mathrm{O}$ decomposition (Esclapez, 2011). This factor, jointly with the retraction of alumina and heat losses, can decrease the reaction temperature in

Figure 6. $\mathrm{D} 15 \mathrm{~L} 70$ thruster duty cycle testing. 


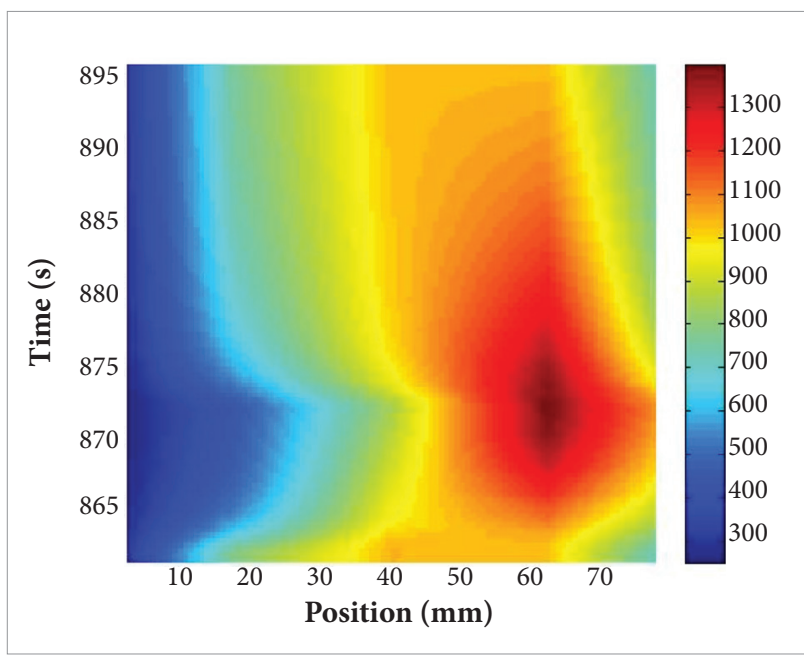

Figure 7. Gas temperature $\left({ }^{\circ} \mathrm{C}\right.$ ) evolution along the catalytic bed and post-chamber section.

the bed. It should be noted that using shorter pulse lengths would provide lower temperatures and a slower degradation of the catalyst.

Figure 8 shows the specific impulse, Is $p=F / \dot{m}$, and the characteristic velocity, $c^{*}=A_{t} P_{c} / \dot{m}$, obtained experimentally. The pulses shown in Fig. 6 were taken as reference, since they were obtained with the thruster in full operation at the start of degradation of the catalyst.

The average specific impulse obtained experimentally was about $1120 \mathrm{~m} / \mathrm{s}$, which is close to the theoretical value, $1220.4 \mathrm{~m} / \mathrm{s}$. Therefore, the average specific impulse efficiency,

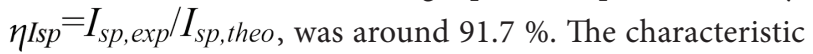
velocity efficiency, $\eta_{c^{*}}=c_{\text {exp }}^{*} / c_{\text {theo }}^{*}$, is shown in Fig. 9. The characteristic velocity value obtained in the experiments was about $970 \mathrm{~m} / \mathrm{s}$, whereas the average theoretical value is about $1102 \mathrm{~m} / \mathrm{s}$, giving an average efficiency of about $88 \%$. Considering the characteristic velocity efficiency obtained experimentally, it is observed that the catalytic decomposition of nitrous oxide in the bed was not complete.

\section{CONCLUSIONS}

An experimental investigation of a monopropellant $2 \mathrm{~N}$ thermal-catalytic prototype thruster using gaseous nitrous oxide was presented. The propellant was decomposed by a catalyst of rhodium oxide supported on alumina, with preheating of both catalyst and propellant by a glow-plug system.

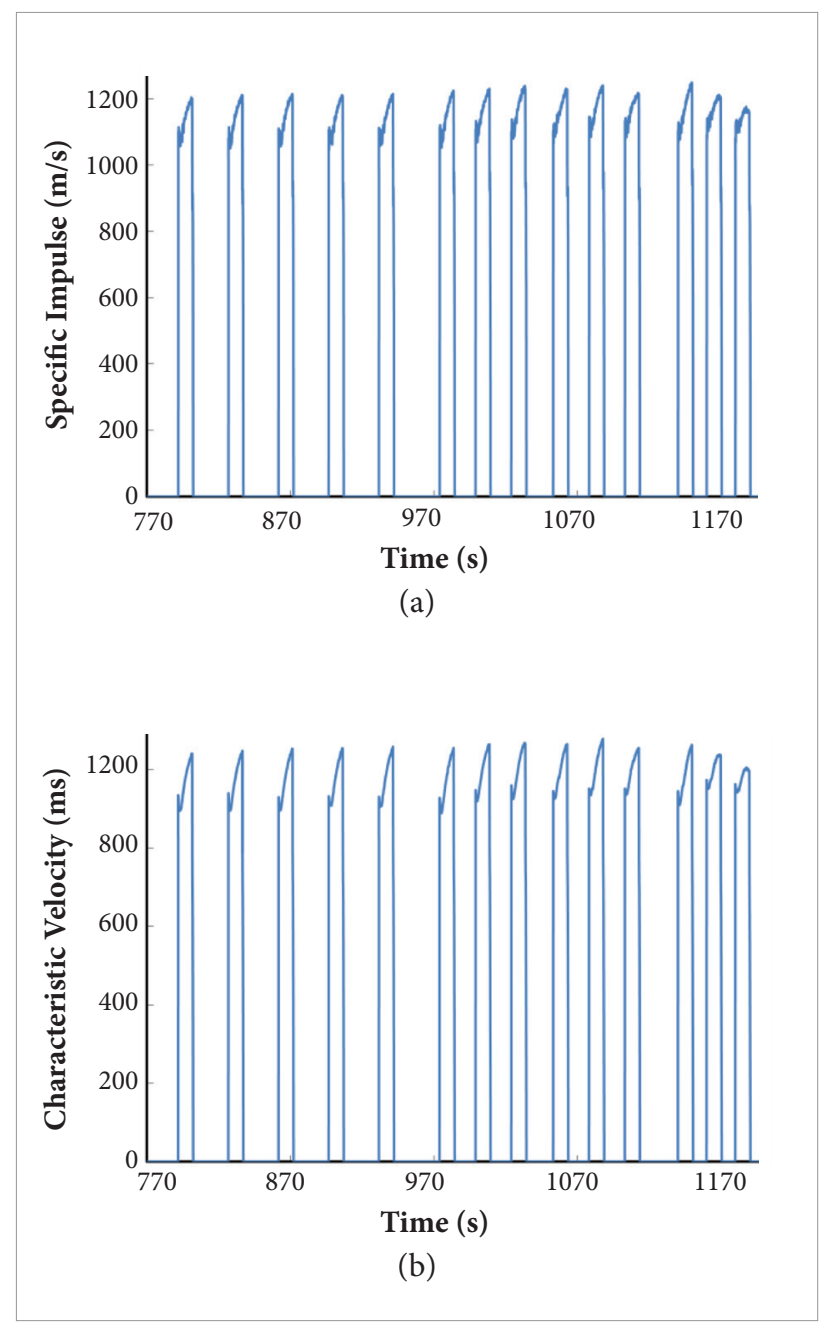

Figure 8. Specific impulse (a) and characteristic velocitie(b).

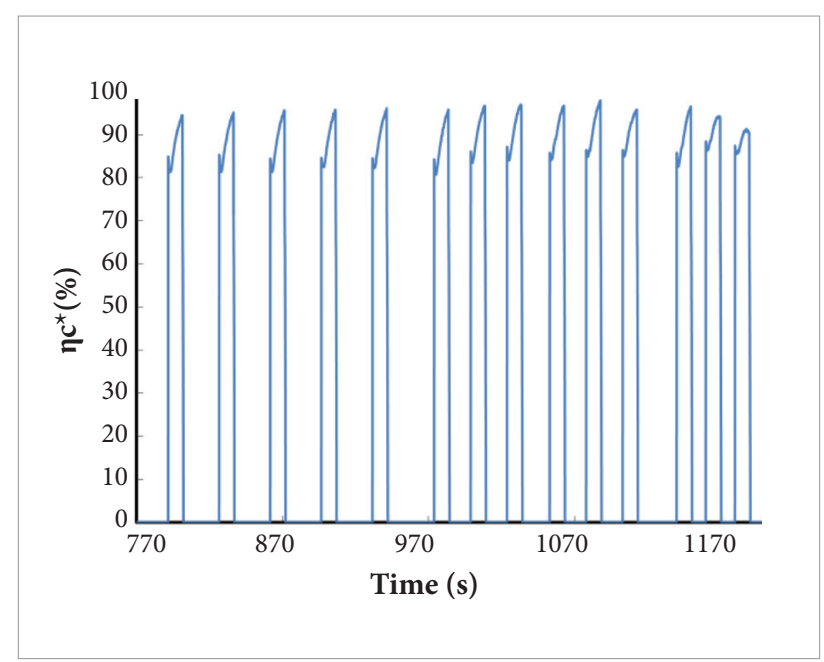

Figure 9. Characteristic velocity efficiency. 
Relatively high decomposition efficiency ( 88\%) was observed prior to catalyst degradation. Changes in the catalytic support preparation are required to reduce the volume loss of the support under the test conditions and to improve catalyst performance for longer firing times. Other factors such as optimization of catalytic bed dimensions, improvements in the injector design and better thermal insulation may increase the thruster's efficiency.

\section{ACKNOWLEDGEMENTS}

The authors acknowledge the Brazilian Conselho Nacional de Desenvolvimento Científico e Tecnológico (CNPq) for providing a doctoral scholarship to the first author and a research grant to the second one. The catalyst preparation was performed with the kind help of Dr. Ricardo Vieira from Brazilian Instituto Nacional de Pesquisas Espaciais (INPE).

\section{REFERENCES}

Amaral, L., 1995, "Química”, Loyola, São Paulo, 23-24.

Arai, H. and Machida, M., 1996, "Thermal stabilization of catalyst supports and their application to High Temperature catalytic combustion". Applied Catalysis A: General, Vol. 138, No. 2, pp. 161-176. doi: 10.1016/0926-860X[95)00294-4

Batta, I., Solymost, F. and Szabo, Z., 1962, "Decomposition of nitrous oxide on some doped cupric oxide catalysts". Journal of Catalysis, Vol. 1, No. 2, pp. 103-112. doi: 10.1016/0021-9517(62)90014-3.

Brown, C.D., 1995, "Spacecraft Propulsion". Ohio: Series Editor-in-Chief. AAIA Education Series. Air Force Institute Technology, pp. 224.

Cai, G., Sun, W., Fang, J., Li, M., Cong,Y. and Yang, Z., 2011, “Design and performance characterization of a sub-Newton $\mathrm{N}_{2} \mathrm{O}$ monopropellant Thruster". Aerospace Science and Technology, Vol. 23, No. 1, pp. 439451. doi: 10.1016/j.ast.2011.10.003.

Esclapez, S.P., 2011, " $\mathrm{N}_{2} \mathrm{O}$ Decomposition rhodium/ceria catalysts: From principles to pratical application", PhD Thesis, Inorganic Chemistry Department, Alicante University, Spain, pp. 201.

Figueiredo, J.L. and Ribeiro, F.R., 1989, "Catálise Heterogênea". Calouste Gulbenkian Foundation, Porto, Portugal, pp. 353.

Junior, J.A., 2009, "Desenvolvimento de um Propulsor Catalítico para Satélites usando Óxido Nitroso como Propelente", Master Thesis, Instituto Nacional de Pesquisas Espaciais - INPE, Cachoeira Paulista, Brazil, pp. 168.

Humble, R.W., Henry, G.N. and Larson, W.J., 1995, "Space Propulsion Analysis and Designer". MacGraw-Hill Companies, Inc., Primis Custom Publishing.

Kapteijn, F., Mirasol, J.R. and Moulijn, J.A., 1996, "Review: Heterogeneous catalytic decomposition of nitrous oxide". Applied Catalysis B: Environmental 9, pp. 25-64. doi: 10.1016/0926-3373(96)90072-7.

Karabeyoglu, A., Dyer, J., Stevens, J. and Cantwell, B., 2008, "Modeling of $\mathrm{N}_{2} \mathrm{O}$ Decomposition Events". American Institute of Aeronautics and Astronautics, 44th AIAA/ASME/SAE/ASEE Joint Propulsion Conference \& Exhibit, Hartford.

Lohner, K., Dyer, J., Doran, E., Dunn, Z., Krieger, B., Decker, V., Wooley, E., Sadhwani, A., Cantwell, B. and Kenny, T., 2007, "Design and Development of a Sub-Scale Nitrous Oxide Monopropellant Gas Generator", American Institute of Aeronautics and Astronautics, Stanford University, Stanford, USA.

Makled, A.E. and Belal, H., 2009, "Modeling of Hydrazine Decomposition for Monopropellant Thrusters". 13th International Conference on Aerospace Sciences \& Aviation Technology, ASAT - 13, Military Technical College, Kobry Elkobbah, Cairo, Egypt.

Merril, C., 2008, "Nitrous Oxide Explosive Hazards", Air Force Research Laboratory, Edwards AFB, CA.
NASA, "Chemical Equilibrium with Applications (CEA)". Cleveland, $\mathrm{OH}$ : Glenn Research. Center NASA, Retrieved on March 5, 2012, from http://www.grc.nasa.gov/WWW/CEAWeb/ceaguiDownloadwin. htm.

Neto, T.G.S., 2011, "Handout catalysis". Instituto Nacional de Pesquisas Espaciais, Curso de Engenharia e Tecnologias Espaciais.

Plumlee, D. and Steciak, J., 2004, “Development of a monopropellant micro-nozzle and lon Mobility spectrometer in LTCC", In: Ceramic Interconnect Technology Workshop, Denver, CO.

Scherson, Y. and Lohner, K. , 2009, "A Monopropellant Gas Generator Based on $\mathrm{N}_{2} \mathrm{O}$ Decomposition for "Green" Propulsion and Power Applications". American Institute of Aeronautics and Astronautics, 45th AIAA/ASME/ SAE/ASEE Joint Propulsion Conference \& Exhibit, Denver, Colorado, EUA.

Sanscrainte, W., 1961, "Hydrogen Peroxide Attitude Control Systems". Planetary and Space Science, Vol. 4, pp. 184-193. doi: 10.1016/00320633(61)90131-3.

Stark, J.P.W.J. and Swinerd, G.G., 2003, "Mission Analysis", In: Fortescue, P., Stark, J. and Swinerd, G., (Eds.), Spacecraft Systems Engineering, $3^{\text {rd }}$ ed., John Wiley \& Sons, pp 111-167.

Sutton, G.P., 2001, "Rocket propulsion elements: an introduction to the engineering of rockets". 7. ed. John Wiley \& Sons, pp. 751.

Vafai, K., 2005, "Handbook of Porous Media". 2 $2^{\text {nd }}$ Edition. Taylor \& Francis Group, LLC, London, UK, pp. 742.

Vieira, R., Cuong, P., Keller, N. and Ledoux, M.J., "Novos Materiais à base de Nanofibras de Carbono como Suporte de Catalisador na Decomposição da Hidrazina”. Química Nova, Vol. 26, No. 5, pp. 665669. doi: 10.1590/S0100-40422003000500008.

Wilson, M.D., Eilers, S.D. and Whitmore, S.A., 2012, "Catalytic Decomposition of Nitrous Oxide Monopropellant for Hybrid Motor Re-lgnition". American Institute of Aeronautics and Astronautics, 48 th AIAA/ASME/SAE/ ASEE Joint Propulsion Conference \& Exhibit, Atlanta, Georgia, USA.

Zakirov, A.V. and Zhang, H., 2008, "A model for the operation of nitrous oxide monopropellant". Aerospace Science and Technology, Vol. 12, No. 4, pp.318-323. doi: 10.1016/j.ast.2007.08.003.

Zakirov, V., Sweeting, M., Goeman, V. and Lawrence, T., 2000, "Surrey research on nitrous oxide catalytic decomposition for space applications". $14^{\text {th }}$ AIAAUSU Conference on Small Satellites, pp. 1-9.

Zakirov, V. and Li, L., 2004, "Small Satellite Propulsion Challenges". European Conference for Aerospace Sciences (EUCASS), Tsinghua University, P.R. China.

Zakirov, V., Sweeting, M., Lawrence, T. and Sellers, J., 2001, "Nitrous oxide as rocket propellant". Acta Astronautica, Vol. 48, No. 5-12, pp. 353-362. doi: 10.1016/S0094-5765(01)00047-9. 